\title{
Research on Low-Carbon City Construction and Development Strategy-A Case Study of Shenzhen
}

\author{
Dan Yao ${ }^{1}$, Jing Luo ${ }^{2}$, Mu Zhang ${ }^{{ }^{*}}$ \\ ${ }^{1}$ Department of Tourism Management, Shenzhen Tourism College of Jinan University, Shenzhen, China; ${ }^{2}$ Department of Business \\ English, Shenzhen Tourism College of Jinan University, Shenzhen, China. \\ Email: yaodan.sztc@gmail.com, luojing@sz.jnu.edu.cn, ${ }^{*}$ zhangmu@163.com
}

Received February $22^{\text {nd }}, 2013$; revised March $22^{\text {nd }}, 2013$; accepted April 22 ${ }^{\text {nd }}, 2013$

Copyright (C) 2013 Dan Yao et al. This is an open access article distributed under the Creative Commons Attribution License, which permits unrestricted use, distribution, and reproduction in any medium, provided the original work is properly cited.

\begin{abstract}
Low carbon economy is full of significance to realize sustainable development of a city. After making a review of global low carbon community construction by summarizing their features and routes, the authors set up a low-carbon economical evaluation system which consists of 3 layers, 3 systems and 14 indicators. What's more, PCA (principal component analysis) and AHP (analytic hierarchy process) are adopted to evaluate the level of low-carbon economic development in Shenzhen. The facts prove that Shenzhen's low-carbon economic development level has formed certain foundation with up tendency in various indicators. Finally, the authors propose suggestions and strategies for developing low-carbon economic development for city of Shenzhen.
\end{abstract}

Keywords: Low Carbon Economy; Low-Carbon City; Evaluation System; Shenzhen

\section{Introduction}

As the concept of low-carbon economy and low-carbon city has gained increasing awareness under the settings of global-warming, many countries and international organizations have been dedicating to advocating lowcarbon life philosophy, exploring low-carbon operation mechanism and setting low-carbon city as the target. Since China is in the progressing development period of urbanization and industrialization, it has to confront with various conflicts while sharing favorable economic success.

Being the core of regional social and economic development, city's growth in industry brings huge amount of emission of green-house gas which becomes an increasing serious problem. Among them, the issue of city resource consumption and environment deterioration has got wide concerns for its significance for life quality and future city. Therefore, it is urgent to reduce city resource consumption and gas emission, and to introduce the idea of low-carbon city to the city planning, construction and development which is profound to adjust the upgrading of industry construction and to improve production and management efficiency.

\footnotetext{
${ }^{*}$ Corresponding author.
}

\section{Research Review and Development Tendency of Low-Carbon City}

So far, there have been no definite and unified criteria for the definition of low-carbon city. The World Wide Fund for Nature defines low-carbon city as the place which can keep resource consumption and carbon dioxide emission at a low level in the rapid economic development. While the Climate Group thinks it is a city that advocates lowcarbon economy to realize low-carbon emission even zero-carbon emission. There are many Chinese scholars striving on the study of low-carbon city. For example, Gu yongxin and Li Hongxin define low-carbon city as the city where the government chooses low-carbon development as development pattern and direction, and the citizens take low-carbon life as ideology and behavior rule, and the management set low-carbon society as construction model and target [1]. Fu Yun regards low-carbon city as an operation model of low-carbon economy by innovating low-carbon technology, changing life style and reducing urban greenhouse gas emission [2]. Jin Shi addresses low-carbon city development should remain resource consumption and carbon dioxide emission at a low level during the fast pace of economy development [3]. It is concluded that low-carbon city is a new channel of the coordination between city's economic develop- 
ment and environmental protection. Many countries have carried out the movement of low-carbon city construction to extend the new idea of low-carbon city. For example, low-carbon community model in Denmark; British urban practice to cope with climate change; Sweden's sustainable plan; Japan's low-carbon society practice plan and America's low-carbon city practice proposal etc. [4]. British Beddington zero energy community and zero-emission community of Sun City, the Netherlands abroad, are two of the more well-known low-carbon model communities: 1) Known as Britain's most innovative residential project "Beddington zero energy consumption Community" Sutton, near London, adhering to the "modern life without sacrificing comfort" concept, so as to become the community more environmentally friendly, more energy efficient [5]. 2) the Netherlands Sun City zero-emission community make extensive use of solar power technology in the roof and exterior walls of buildings to install solar panels to generate electricity. Generating capacity is not only to meet the electricity needs of the community, but also $44 \%$ of the electricity can be delivered to the grid [6]. Foreign scholars also carried out a series of studies on low-carbon cities: Wynn Chi and Nguyen Cam paint out that the concept of low-carbon cities derives from the climate change awareness and the urgent quest to reduce, if not neutralise, anthropogenic-induced carbon emission to the atmosphere [7]. Wei-Ting Chen and Chi-Min Shu think that $\mathrm{CO}_{2}$ reduction is very important for low carbon community and they take Tannan as a case study [8]. but also many foreign scholars select one city as a case study to explore how to build a low-carbon cities. Maribel Feliciano and David C. Prosperi take Florida as an example and provide some pith for the discussion of planning for low carbon cities [9]. Tokyo, Seoul, Shanghai and other cities have been studied by scholrs.

At present, there are 287 prefectural-level cities in China. Till 2008, there exist 13 cities with population over 4 million, 28 cities with 2 to 4 million people, 81 cities with 100 to 200 million people. According to the criteria of megalopolis by the United States, a city with more than 1 million people, $43 \%$ of Chinese cities belong to megalopolis. The statistics in 2008 indicates that GDP of prefectural-level cities has reached RMB 18627.95 billion which occupies $62 \%$ in the total sum of China GDP. City's role as regional center is increasingly significant. However, cities have shown its weakness in the process of rapid urbanization. For instance, total income of average citizen ranks 210 in 2008, coal and steel consumption is No.1 in the world, oil consumption is No.5 all over the world [10]. Moreover, dominant role of Second industry, especially high-consumed industry leads to the increase of resource consumption which finally results in serious environmental problem. What's more, the lower proportion of the third industry in urban economy, the more unreasonable urban economic structure, as well as the more highly-consumed industries are, the greater stress from urban resource will be. In addition, there are also the severe pollution of urban air pollution, deterioration of water quality, traffic noise and urban solid trash increasing [11]. The facts prove that present economy growth pattern of China city still greatly depends on manufacture centered with resource consumption. In order to realize the upgrading of urban industrial structure, energy saving and emission reduction, it is necessary to increase the proportion of the 3rd industry-based service economy in urban economy, and to set the target of constructing low-carbon city in city planning.

\section{Profile of Studied Area}

\subsection{Introduction of Economic Development of Shenzhen}

As special district benefiting from China's reform and opening policy, Shenzhen's GDP reached RMB 820.131 76 in 2009, and increased 4167 times comparing with RMB 0.19638 ever since [12]. Now everybody admits that it is a brilliant economy success. Though this city has created the miracle of "Shenzhen speed", its industry mainly depends on extensive economic growth model in raw material processing. What's more, 30-year fast development has substituted for gradual development which causes problems of population explosion, resource shortage, environmental pollution etc. At present, Shenzhen is at the crucial stage of transformation of economic structure and growth model. It must be confronting with the challenges and opportunities as well. Therefore, the question of how to turn Shenzhen's economy from traditional extensive mode to intensive one, from quantity expansion to quality growth has become a challenge for all the people in Shenzhen City.

\subsection{Resource and Environment Development in Shenzhen}

The result from Shenzhen Bureau of Statistics indicates that the population of residents has increased from 314 thousand to 8.9123 million during 1979-2009 with average speed of $11.8 \%$. In 2009, power consumption of the city increased by $208 \%$ since ten years ago, and water supply goes up by $63 \%$. What's more, large population pushes resource and raw material consumption to a higher level [13].With the development of 2nd industry, high-costly energy industry grows as well, total energy consumption rises regularly every year. Present industry situation of Shenzhen and China's resource structure has determined coal-centered resource consumption pattern, that is, it will produce 4.12 tons of $\mathrm{CO}_{2}$ by burning one ton of coal, which will produce more $\mathrm{CO}_{2}$ by $30 \%$ than 
those produced from petrol and $70 \%$ from natural gas [14]. In 2009, raw coal consumption was 2.62106292 tons which was No. 1 in main resource consumption list. From 1979 to 2009, Shenzhen's total output value has increased by $4175 \%$, whilst the proportion of environment protection has only gone up 53\% [12]. It is obvious that there is a regular increase in resource consumption and $\mathrm{CO} 2$ emission which results in severe environmental problem during the process of fast urbanization of Shenzhen City.

In 2008, Development and Reform Committee drew up "Reform and Planning plan in Zhujing Delta" which addresses the importance of energy saving and environment protection. As a key city in Zhujiang Delta, Shenzhen should set a good example in this work. Therefore, in a government report of 2010 , it proposed to speed up the construction of national eco-cultural demonstrative city and national low-carbon eco-demonstrative city in five years. It also planed to promote energy-saving and emission-reduction in public organization, and to advocate low-carbon life-style to enhance eco-cultural awareness. In this way, it is able to construct a low-carbon city free of constraints from resource and protection which matters much for Shenzhen.

\section{Design of Evaluation Indicator System of Low-Carbon City Development Potential}

Since constructing low-carbon economy evaluation index is an important stage for building low-carbon city, it is an initial step and significant presupposition to choose an appropriate index to evaluate city's potential to develop low-carbon economy. What's more, it is also an important step to transfer theory to practical level, which matters the establishment of low-carbon city and channel choice of city low-carbon economic development.

According to "Evaluation System of Low-carbon City in China", this system refers that it should be composed of 10 indexes, such as city low-carbon development planning index, city green land coverage index, low-carbon travel index, city air quality index, city direct carbonreduction index etc. [15]. Xue Meng think the establishment of low-carbon city evaluation index should focus on three aspects, that is, production channel, coordination degree between carbon-emission reduction quantity and economy development, government policy enforcement [16]; Xu Hong has designed a city sustainable development evaluation index system which is made up of $3 \mathrm{lev-}$ els, 4 systems and 23 specific indexes [17]. Shao Chaofeng has adopted the model of drive-stress-state-influence-response and constructed the system of 5 categories and 13 elements [18].

Referring to Shenzhen's reality, starting from three levels of economy, low-carbon and social development, the authors chose 14 elements in Shenzhen low-carbon city development potential evaluation index system (see Table 1). What's more, the authors analyzed and evaluated Shenzhen's potential on constructing low-carbon city by referring to the statistics from 2005-2009 and adopting main-element analysis and level analysis.

Table 1. Shenzhen evaluation indicator system of low-carbon city.

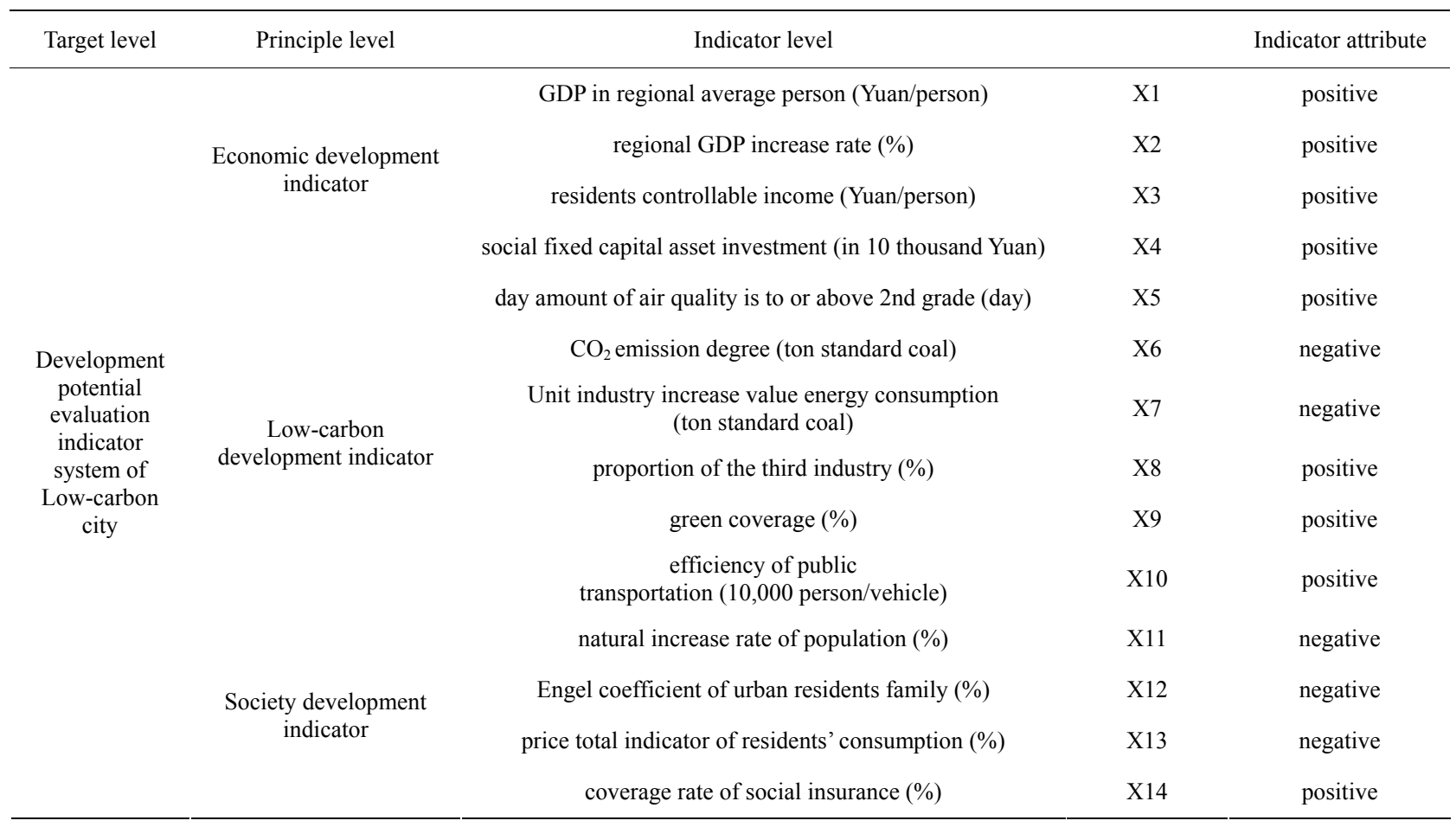




\subsection{Evaluation of Economy Development of Shenzhen}

According to the above evaluation indicator system and statistics of 2005-2009 in Shenzhen, Table 2 comes into being as follows.

There comes a relevant matrix as Table 3 with correlation analysis:

The above correlated matrix indicates the correlation coefficients of X1 and X3, X1 and X2, X1 and X4, X3 and $X 4$ are $0.973,0.871,0.919,0.981$ with the absolute value more than 0.8 , which shows high correlation degree. Therefore, we can have main elements analysis on these repetitive indexes to figure out various principal component factors representing comprehensive situation of economic development level.

As indicated in Table 4, the value of KMO is 0.627 , which can be evaluated with principal component analysis.

Table 5 shows that the contribution rate of the first

Table 2. The situation of economic development in Shenzhen.

\begin{tabular}{cccccc}
\hline & 2005 & 2006 & 2007 & 2008 & 2009 \\
\hline $\begin{array}{c}\text { X1 Yuan/ } \\
\text { Person) }\end{array}$ & 60,507 & 67,907 & 79,221 & 89,814 & 92,771 \\
$\begin{array}{c}\text { X2 (\%) } \\
\begin{array}{c}\text { X3 (yuan/ } \\
\text { person) }\end{array} \\
\begin{array}{c}\text { X4 (yuan } \\
\text { in 10 }\end{array} \\
\text { thousand) }\end{array}$ & $11,14910,810,542$ & 16.60 & 14.80 & 12.10 & 10.70 \\
\hline
\end{tabular}

Statistic source: statistic annual of Shenzhen 2005-2009.

Table 3. Correlation coefficient matrix.

\begin{tabular}{ccccc}
\hline & $\mathrm{X} 1$ & $\mathrm{X} 2$ & $\mathrm{X} 3$ & $\mathrm{X} 4$ \\
\hline $\mathrm{X} 1$ & 1 & -0.871 & $0.973^{* *}$ & $0.919^{*}$ \\
$\mathrm{X} 2$ & -0.871 & 1 & $-0.918^{*}$ & $-0.901^{*}$ \\
$\mathrm{X} 3$ & $0.973^{* *}$ & $-0.918^{*}$ & 1 & $0.981^{* *}$ \\
$\mathrm{X} 4$ & $0.919^{*}$ & $-0.901^{*}$ & $0.981^{* *}$ & 1 \\
\hline
\end{tabular}

“"” means that the absolute value more than 0.9 , which shows high correlation degree; " " means that the absolute value more than 0.95 , which shows higher correlation degree.

Table 4. KMO and bartlett's test.

\begin{tabular}{ccc}
\hline \multicolumn{3}{c}{ KMO and Bartlett's Test } \\
\hline Kaiser-Meyer-Olkin Measure of Sampling Adequacy. & 0.627 \\
& Approx. Chi-Square & 17.060 \\
Bartlett's Test of Sphericity & df & 6 \\
& Sig. & 0.009 \\
\hline
\end{tabular}

principal component reaches $94.569 \%$. The initial factor loading will work out relative character value to achieve principal component function expression as the economic development index so as to gain graph of economic development of Shenzhen in the year of 2005-2009.

In Table 6, the column vector of main principal component divided by $\sqrt{\lambda_{1}}$, which will get standardized principal component of economic development index.

$$
F_{1}=0.512 z x_{3}+0.503 z x_{4}+0.498 z x_{1}-0.487 z x_{2}
$$

Figure 1 indicates that Shenzhen's economy presents a trend of steady growth during 2005-2009. Especially since 2006, there has witnessed a rapid increase. It is therefore concluded that Shenzhen's total output value, social fixed capital investment and average controllable income increase continuously, which is a positive sign of economic development.

\subsection{Evaluation of Low-Carbon Development Level of Shenzhen}

The following statistics (see Table 7) studies low-carbon development level in Shenzhen during 2005-2009.

Table 5. The matrix of total variance explaination.

\begin{tabular}{|c|c|c|c|c|c|c|}
\hline & $\begin{array}{l}\text { Feature } \\
\text { value }\end{array}$ & $\begin{array}{c}\text { Contribution } \\
\text { rate }\end{array}$ & $\begin{array}{c}\text { Accumulated } \\
\text { contribution } \\
\text { rate }\end{array}$ & $\begin{array}{l}\text { Feature } \\
\text { value }\end{array}$ & $\begin{array}{c}\text { Contribution } \\
\text { rate }\end{array}$ & $\begin{array}{c}\text { Accumulated } \\
\text { contribution } \\
\text { rate }\end{array}$ \\
\hline 1 & 3.783 & 94.569 & 94.569 & 3.783 & 94.569 & 94.569 \\
\hline ? & 0.139 & 3.483 & 98.052 & -- & -- & -- \\
\hline & 0.076 & 1.891 & 99.943 & -- & -- & -- \\
\hline 4 & 0.002 & 0.057 & 100.000 & -- & -- & -- \\
\hline
\end{tabular}

Table 6. The matrix of initial factor loading.

\begin{tabular}{cc}
\hline & Principal component 1 \\
\hline X3 & 0.996 \\
X4 & 0.978 \\
X1 & 0.968 \\
X2 & -0.948 \\
\hline
\end{tabular}

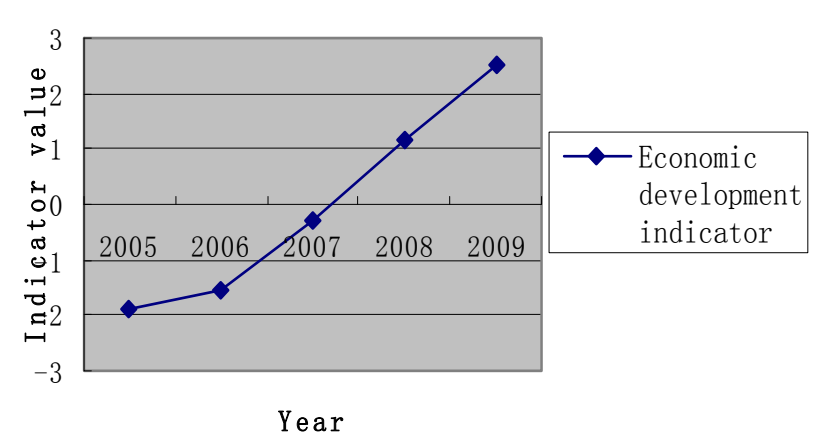

Figure 1. Shenzhen economic development indicator value. 
In terms of positive and negative contribution from various indexes in evaluation system, we can calculate negative index with its reciprocal to indicate negative influential characteristics of this index.

Detailed Analysis process of low-carbon development level is deleted for its similarity with evaluation method of economic development. There only lists standardized low carbon development index principal component expression:

$$
\begin{aligned}
F_{2}= & 0.429 z x_{6}+0.428 z x_{7}+0.425 z x_{8}-0.402 z x_{9} \\
& +0.393 z x_{5}+0.369 z x_{10}
\end{aligned}
$$

Figure 2 indicates that Shenzhen's low-carbon development level matches with economic development level during 2005-2009 with up-tendency. People can predict a gradual growth of the third industry, reduction of emission of $\mathrm{CO}_{2}$, improvement of urban air quality, and expansion of city green coverage. All of these tell the truth that the government of Shenzhen is striving for solving the contradiction between production and environmental protection.

\subsection{Evaluation of Social Development of Shenzhen}

The following data will be used to analyze Shenzhen's

Table 7. Low-carbon development in Shenzhen.

\begin{tabular}{cccccc}
\hline & 2005 & 2006 & 2007 & 2008 & 2009 \\
\hline X5 (number of day) & 360 & 359 & 361 & 364 & 364 \\
X6 (tons of standard coal) & 0.448 & 0.435 & 0.423 & 0.411 & 0.400 \\
X7 (tons of standard coal) & 0.598 & 0.572 & 0.551 & 0.530 & 0.511 \\
X8 (\%) & 46.4 & 47.3 & 49.7 & 50.3 & 53.2 \\
X9 (\%) & 97642 & 97625 & 97608 & 97605 & 97598 \\
$\begin{array}{c}\text { X10 (in 10,000 } \\
\text { persons/vehicles) }\end{array}$ & 16.68 & 16.85 & 16.57 & 17.35 & 18.69 \\
\hline
\end{tabular}

Data source: "Statistic annual of Shenzhen 2005-2009", there is no statistics for GDP in 10,000 RMB and $\mathrm{CO}_{2}$ emission degree. According to the calculation method: GDP in 10,000 RMB and $\mathrm{CO}_{2}$ emission degree $=10,000$ RMB GDP energy costing. "Emission index of raw coal is $0.7559(104 t / 104 t)$ (IPCC, 2006).

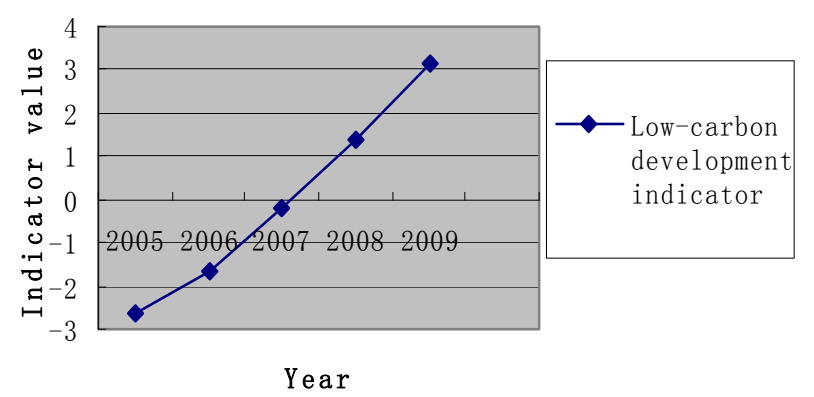

Figure 2. Shenzhen low-carbon development indicator value. social development situation (see Table 8).

Detailed Analysis process of social development level is again deleted for its similarity with calculation expression of synthetically index. And there only lists standardized low carbon development index principal component expression:

$$
F=\frac{\lambda_{1}}{\sum \lambda} F_{1}+\frac{\lambda_{2}}{\sum \lambda} F_{2}=0.706 F_{1}+0.294 F_{2}
$$

It can be concluded from Figure 3 that there is a fluctuation in Shenzhen's social development. During 20052007, there was a steady but slight declining trend in development. While the year of 2008 suffered a sharp drop resulting from high birth rate, which affected average distribution of social resource. What's more, general rise of food price led to the increase of food consumption which brought the climbing of residents' family Engel Coefficient to result in the dramatic decline of Shenzhen's social development index in 2007-2008. Although there happened the global financial crisis in 2009, residents' controllable income reacted with price level, which led to the reduction of residents' family Engel coefficient. What's more, the effective control of inflation and reduction of birth rate encouraged a rapid recovery of Shenzhen's social development indicator.

Comparing with the gradual increase of economic and low-carbon development indicators, the trend of social development indicator proves that citizens in Shenzhen have to work hard to keeping the balance among economic, low-carbon and social development.

\subsection{Comprehensive Evaluation of Low-Carbon Economic Development of Shenzhen}

Hierarchy analysis is adopted to evaluate Shenzhen's general economy, low-carbon and society development level to get the weights to figure out comprehensive index of low-carbon economic development of Shenzhen during 2005-2009.

$$
W=\{0.5028,0.2584,0.2387\}
$$

then the authors used Delphi method and questionnaire by inviting 19 professionals in the field to work out professional comparative judgment matrix. What's more, we

Table 8. Social development in Shenzhen.

\begin{tabular}{cccccc}
\hline & 2005 & 2006 & 2007 & 2008 & 2009 \\
\hline X11 (\%) & 11.23 & 11.44 & 13.45 & 13.14 & 12.84 \\
X12 (\%) & 33.4 & 33.3 & 32.5 & 36.0 & 35.0 \\
X13 (\%) & 101.6 & 102.2 & 104.1 & 105.9 & 98.7 \\
X14 (\%) & 61.2 & 65.8 & 75.3 & 80.8 & 84.3 \\
\hline
\end{tabular}

Data source: "statistics annual of Shenzhen 2005-2009". 


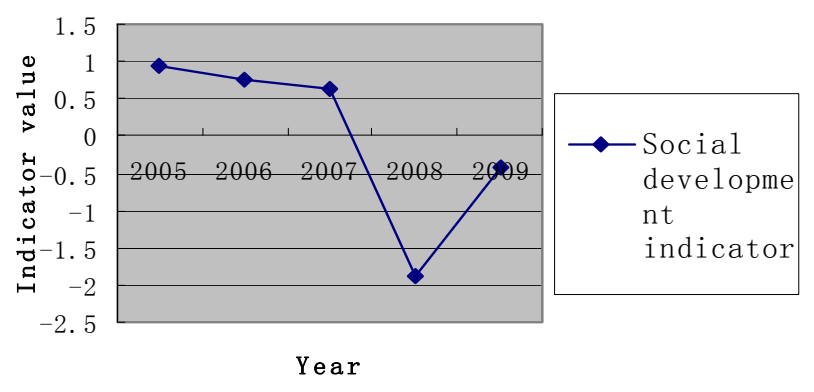

Figure 3. Shenzhen social development indicator value.

handed out more than 400 on-line questionnaires to collect people's opinions, and finally combined various of information with deleting wrong data to attain the comprehensive judgment matrix as follows (see Table 9).

All the data are input in Matlab system to figure out the results as follows:

$$
\begin{gathered}
a=[1,2.065,1.984 ; 0.484,1,1.149 ; 0.504,0.87,1] \\
{[x, y]=\text { eig }(a) ;} \\
\text { eigenvalue }=\operatorname{diag}(y) ; \text { lamda }=\text { eigenvalue }(1) \\
c i=(\operatorname{lamda}-3) / 2 ; \\
c r=\operatorname{ci} / 0.58 ; \\
w=x(:, 1) / \operatorname{sum}(x(:, 1))
\end{gathered}
$$

It is concluded that:

$$
\lambda_{\text {max }}=3.0032 ; C I=0.0016 ; C R=0.0028
$$

$C R<0.1$, then consistency test has been approved;

$\lambda_{\max }$ 's eigenvector is low-carbon economic composite index, the formula is:

$$
Y_{k}=\sum_{i=1}^{3} w_{i} y_{k}^{i}
$$

Combining various index data of Shenzhen during 2005-2009, the authors worked out Shenzhen's lowcarbon economic composite development index (see Table 10).

Table 9. Indicators matrix of shenzhen economy, low-carbon, social development.

\begin{tabular}{cccc}
\hline & $\begin{array}{c}\text { Economic } \\
\text { Development } \\
\text { indicator }\end{array}$ & $\begin{array}{c}\text { Low-carbon } \\
\text { development } \\
\text { indicator }\end{array}$ & $\begin{array}{c}\text { Social } \\
\text { development } \\
\text { indicator }\end{array}$ \\
\hline $\begin{array}{c}\text { Economic } \\
\text { development } \\
\text { indicator }\end{array}$ & 1 & 2.065 & 1.984 \\
$\begin{array}{c}\text { Low-carbon } \\
\text { development } \\
\text { indicator }\end{array}$ & 0.484 & 1 & 1.149 \\
$\begin{array}{c}\text { Social } \\
\text { development } \\
\text { indicator }\end{array}$ & 0.504 & 0.87 & 1 \\
\hline
\end{tabular}

The comprehensive indicator of economic, low-carbon and social development describes a steady up-tendency in Shenzhen's low-carbon economic growth during 20052009. However, social development once fluctuated or even declined. Especially, in 2007-2008, poor performance of social development level affected economic growth. However, in 2009, the recovery of social development level indicator encouraged the growth of Shenzhen's composite development one (see Figure 4). Therefore, it can be concluded that the coordination and cooperation among economic, low-carbon and social development play as a significant role in strengthening comprehensive competitiveness of Shenzhen.

Hence, it is summerzied that Shenzhen should keep long-term coordinative development of economy, lowcarbon and society to realized the goal of low-carbon city construction, which needs to learn from the past, take advantage of city's strength with combining Shenzhen's characteristics.

\section{Shenzhen's Strategy on Constructing Low-Carbon City}

It is suggested that people should make full use of Shenzhen's advantage in resource and policy to clarify city strategic target to make the plan on low-carbon economic development:

- Attaching importance on low-carbon city construction plan in overall consideration with characteristics. It is

Table 10. Shenzhen comprehensive development of lowcarbon economy indicators.

\begin{tabular}{ccccc}
\hline Year & $\begin{array}{c}\text { Economic } \\
\text { development } \\
\text { indicator }\end{array}$ & $\begin{array}{c}\text { Low-carbon } \\
\text { development } \\
\text { indicator }\end{array}$ & $\begin{array}{c}\text { Social } \\
\text { development } \\
\text { indicator }\end{array}$ & $\begin{array}{c}\text { Comprehensive } \\
\text { indicator }\end{array}$ \\
\hline 2005 & -1.87 & -2.66 & 0.93 & -1.41 \\
2006 & -1.53 & -1.67 & 0.75 & -1.02 \\
2007 & -0.27 & -0.17 & 0.62 & -0.03 \\
2008 & 1.18 & 1.39 & -1.89 & 0.50 \\
2009 & 2.50 & 3.12 & -0.41 & 1.97 \\
\hline
\end{tabular}

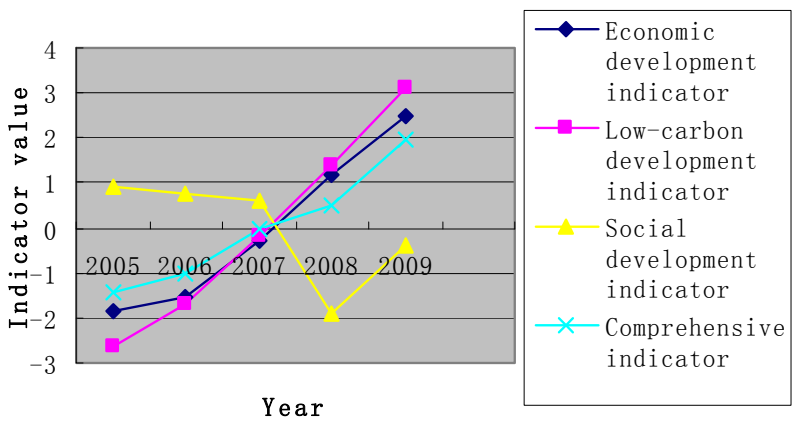

Figure 4. Comparison of Shenzhen low-carbon economic development indicators. 
suggested to arrange and to construct low-carbon economic system during the 12 th five-year plan. It will create a positive environment for its low-carbon economic transformation in the aspects of industrial structure adjustment, regional arrangement, technical progress and infrastructure. Especially in industrial adjustment, low-carbon strategy should be deeply integrated in the 12th five-year plan, and set low-carbon criteria as the standard and measurement. What' more, development in the third industry is supposed to be quickened with a reducing proportion of the second industry in economy. It aims to increase the proportion of the third industry to $65 \%-75 \%$ in 2020 , high-technology should be transferred from processing-oriented to R\&D-oriented industry to develop a headquarter economy and modern service industry.

- Transferring present industrial layout, optimizing industrial structure of Shenzhen. Though Shenzhen's high-technology industry develops steadily, there still exists some hidden structural security problems, and the role as a dominant part of electronic information manufacture industry has hardly been changed for a long time. As electronic information manufacture industry is changing from high-technological industry to general manufacture, product's overall added value is decreasing sharply [19]. There presents strong liquidity and substitution, overdependence on it, which will bring visible danger to industrial structure. Therefore, it is necessary to foster new industry backbone and economic growth point. In addition, it should increase the support in the field of recycled industry, energy-costing industry, energy-service industry etc., such as offering more grants for electric car, solar photovoltaic cells and LED lightening products.

- Being driven by new low-carbon technology, constructing low-carbon city. Technology development on clean energy should be listed in the future supporting technology field of Shenzhen government [20]. People should evaluate the feasibility of building low-carbon technology investment funds, focus on government's input in resource, and promote recycled energy technology development together with transformation on low-carbonized technology.

- Developing and carrying out strictly low-carbon production technology criteria, putting them into city production guidance. It is suggested to set up and to promote "urban ecological and green responsibility system of Shenzhen" to clarify the responsibility of low-carbon economic operation. On the base of "Shenzhen Index of industrial structure optimization and production guidance", it is necessary to establish the entrance standard of low-carbon industry foundation by listing low-carbon criteria into environmental evaluation regulation. What's more, by setting up "low- carbon production management criteria of Shenzhen", people can entitle the qualified products and service with "low-carbon" logo. Moreover, object-oriented low-carbon economic statistics and evaluation system will be established, and low-carbonized strategic target and evaluation index system, the potential of green-gas emission reduction, cost and efficiency will be deeply studied.

- Striving for constructing complete carbon financial market, and expanding financing channel. Shenzhen tries to make full use of the platform of Shenzhen Trade centre to establish carbon emission trade system. Carbon market system is a significant innovation to put green-gas emission under control, which is also a crucial economic strategy for various countries to control total emission of green-gas. What's more, the rich resource of Shenzhen will be adopted to set up Shenzhen carbon trade platform with market approach, then an inter-provincial "carbon resource \& carbon sinks" trade market, and then an inter-enterprise carbon trade market throughout the country, finally a global carbon trade center can be achieved in Shenzhen.

\section{Conclusion}

A city's development of low-carbon economy should be evaluated in the following three aspects: which is development level in economy, low-carbon and society. Therefore, the authors designed a city low-carbon evaluation system composing of 3 sub-systems, 14 specific indexes. This system proves that Shenzhen's economic development indicators were $-1.87,-1.53,-0.27,1.18$ and 2.50 during 2005-2009 with an up-tendency; Shenzhen's low-carbon development indicators were separately $-2.66,-1.67,-0.17,1.39$ and 3.12 during 2005-2009, which is also experiencing a positive trend. While Shenzhen's social development indicators were $0.93,0.75$, $0.62,-1.89$ and -0.41 during the same five years, among which a drop in 2008 is found. Taking these three indicators into consideration, we can see that Shenzhen's comprehensive economic development indicators were $-1.41,-1.02,-0.03,0.50$ and 1.97 during the same period, which is a sign to show that there is a certain basis for Shenzhen's low-carbon economic construction with growing trend. Nevertheless, there is still a long way to go for Shenzhen's low-carbon construction still needs hard work hard on adjustment and upgrading in industrial construction, and fulfillment of urban cultural connotetion to eventually realize the target of low-carbon city construction.

\section{Acknowledgements}

This paper is supported by the 2012 teaching quality and 
reform Project of Guangdong Province and the 2012 Key project of Teaching Reform of Jinan University: Research on the Integration of tourism Management undergraduate international perspective nurture and practice teaching platform construction.

\section{REFERENCES}

[1] Y. X. Gu and H. X. Li, "The Thoughts on 'Low-Carbon City'," Construction Information in China, Vol. 16, No. 8, 2008, pp. 24-25.

[2] Y. Fu, Y. L. Wang and D. Li, "The Study on Development Route of Low-Carbon City," Science's Impact to Society, No. 2, 2008, pp. 5-9.

[3] S. Jin, "WWF Starts Chinese Low-Carbon City Development Project," Environment Protection, Vol. 3, No. 3, 2008, p. 22.

[4] C. Z. Sun, J. F. Liu and G. L. Zhang, "Development Model and Construction Channel of Low-Carbon City," Innovative Science, No. 12, 2010, pp. 26-27.

[5] Z. P. Xin and Y. T. Zhang, "low-Carbon Economy and Low-Carbon City," Urban Development, No. 4, 2008, pp. 98-102.

[6] "Low-Carbon Urban Green Practice-Reports from Overseas," Wen Hui Newspaper, 9 February 2010.

[7] W. Chi and N. Cam, "Fostering Interconnectivity Dimension of Low-Carbon Cities: The Triple Bottom Line ReInterpretation," Habitat International, Vol. 37, 2013, pp. 88-94. doi:10.1016/j.habitatint.2011.12.020

[8] W.-T. Chen and C.-M. Shu, "CO 2 Reduction for a LowCommunity: A City Perspective in Taiwan," Separation and Purification Technology, Vol. 94, 2012, pp. 154-159. doi:10.1016/j.seppur.2011.06.004

[9] M. Feliciano and D. C. Prosperi, "Planning for Low Carbon Cities: Reflection on the Case of Broward County,
Florida, USA," Cities, Vol. 28, 2012, pp. 495-497.

[10] National Bureau of Statistics, "Annual of Statistics of China," Statistics Press of China, Beijing, 2009.

[11] S. Yin, "Experience and Inspiration on Industrial Structure Adjustment in Advanced Countries," Modern Business, No. 30, 2010, p. 84.

[12] Shenzhen Bureau of Statistics, "Annual of Statistics in Shenzhen," Statistics press of China, Beijing, 2009.

[13] L. J. Gu, "Low-Carbon City: A New Idea of Urbanization in China," Future and Development, No. 3, 2010, pp. 2-5.

[14] Y. F. Wang, "Study on Evaluation system of Low-Carbon City: Master Dissertation," M.S. Thesis, Hebei University, Shijiazhuang, 2010.

[15] Media Alliance of China Low-Carbon Economy, "Media Alliance Standard of China Low-Carbon Economy. MB/ C 001-2011. Evaluation System of Low-Carbon in China," Media Alliance of China Low-Carbon Economy, Beijing, 19 January 201.

[16] M. Xue, "Evaluation Index System of Low-carbon City," Chinese Market, No. 45, 2010, pp. 121-123.

[17] H. Xu, "Establishment of Scientific Urban Sustainable Development Index System," Study on Urban Development, No. 3, 2004, p. 49.

[18] C. F. Shao and M. T .Ju, "Study on DPSIR-Based LowCarbon City Index System," Ecology Economy, No. 10, 2010, pp. 95-99.

[19] Dong Xiao, "On inclusive market system of the circular economy," Ph.D. Thesis, Fudan University, Shanghai, 2006.

[20] S. Shao and G. H. Ma, "Shenzhen Circular Economy Development Status Evaluation," Industrial Technology Economy, No. 11, 2011, pp. 128-130. 